\title{
Analysis and Countermeasure Research on Psychological Problems of Contemporary College Students
}

\author{
Yan Li \\ College of Intelligent Science and Information Engineering \\ Xi'an Peihua University \\ Xi'an, China
}

\begin{abstract}
For contemporary college students, mental health is the basis of academic success, happy life and successful career. College students are a special group with high self-orientation and strong desire for success, but their mental development is not yet mature and stable. At present. With rapid development of modern society, college students are facing various social, family, learning and employment problems. Their psychological quality is facing severe challenges. The psychological problems of contemporary college students are becoming increasingly prominent. This paper analyses the psychological problems of college students through investigation, studies the causes and external environment, and puts forward more feasible solutions.
\end{abstract}

Keywords-College students; Mental health; Reason; Countermeasures

\section{INTRODUCTION}

College students are praised as "the pride of the times", "the darling of the society", and parents are right about it. Its high expectations, hope that the son Jackie Chan, hope that the woman into the phoenix. Today, with the rapid development of society, Their mental health is very worrying. In recent years, due to psychological inquiry. The crime and suicide cases of college students caused by the questions often occur. Around college students, The theme of mental health, using the Internet, surveys, access to information and other means of University. The mental health of the students was investigated. We want to adjust the mental health of College students. To find out some common psychological problems faced by contemporary college students. This paper puts forward effective methods to solve this problem.

\section{RESEARCH AND ANALYSIS}

A questionnaire survey was conducted among 200 students. The investigation and analysis are as follows:

(1) How about the current college life adaptation?

\section{A. Very good B. Can also C. Poor D. Poor}

Through investigation and analysis, $60 \%$ of the students'adaptability is still good, which shows that most of them are able to adapt. The students with grades have better

\author{
Jinhuan Wang \\ College of Intelligent Science and Information Engineering \\ Xi'an Peihua University \\ Xi'an, China
}

adaptability. $15 \%$ of the students' sense of adaptation to college life. Ten percent of the students felt bad about the adaptation of college students to life. More help and encouragement are needed. life?

(2) How do you think stress affects you in your study and
A. No impact, it can increase learning motivation.
B. A little influence, not affect learning, life
C. A little influence on study and life
D. Has a great influence, unable to study and live normally.

According to the survey and analysis, $46 \%$ of the students thought that stress had no effect and could be used. In order to increase learning motivation, more optimistic and positive. $32 \%$ of the students thought it had some influence. But it will not affect learning and life, indicating that they can crowd out and overcome pressure, $10 \%$ Students think that stress has a great impact on them, which will lead to their inadvertent learning and explain them. Psychological quality is not good.

(3) What is your interpersonal relationship with your classmates?

\section{A. Good B. General C. Poor D. Obstacles}

According to the survey and analysis, $17 \%$ of the students have poor communicative competence and some obstacles, and $60 \%$ have some obstacles. Students have good communicative competence, $23 \%$ of them have good communicative competence.

(4) Who do you turn to first when you are under pressure?

\section{A. Family B. Friends \\ C. Professionals D. School Advisory Institutions}

Through investigation and analysis, $40 \%$ of the students will find their parents when they are in trouble to explain them. Their dependence psychology is still very strong, 52\% of the students think it is better to find friends, which is Class students have strong ability of self-living, and need to be able to alleviate and deal with pressure. Depending on professionals

Subsidy Project at School Level of Xi'an Peihua University(No.PHKT18065) 
and School Advisory bodies.

(5) Will there be any idea of hurting the other party after losing love?

\section{A. No B. Yes C. It depends.}

Through investigation and analysis: $70 \%$ of the students will not do the problem of lovelorn College students. Excessive behavior injures the other party. $8 \%$ of the students depend on the situation, and $12 \%$ of the students have unions. These students should give care and psychological guidance to the students who act excessively to hurt the other party.

Through the questionnaire analysis of the above five questions, we can see the vast majority of them. When students are faced with psychological problems, they have strong ability of self-regulation and can pass through the society. Activities relieve stress, but some students are facing psychological problems due to personality and other reasons. Self-regulation ability is poor when problems occur. If it is not adjusted in time, it may lead to psychological problems. Diseases, schools and society should pay attention to.

\section{SOLUTIONS}

How to make them solve problems with positive, optimistic and normal psychology. Problem and prevention of psychosomatic diseases can be strengthened from the following three aspects:

\section{A. Promoting Their Psychological Regulation Ability}

The emergence of any person's psychological problems is the result of the joint influence of external environmental factors and their own factors, and the decisive factor is their own factors. Therefore, the realization of College Students' mental health, first of all, should start from themselves, carry out self-education, enhance their ability of psychological regulation and control, and grow healthily in a complex social environment. Self-education refers to the activities that people consciously, purposefully and actively promote selfdevelopment according to the quality requirements of social development.

\section{1) Cultivate correct self-consciousness and establish correct life goals}

Self-awareness includes self-awareness, self-experience, self-control and so on(1). As the post-90s College students, they have strong self-awareness and good self-feeling. Their evaluation and expectations are generally high, lacking objectivity and correctness, and often deviate from the actual level. Therefore, they are often in a state of self-esteem and pride, and when they encounter problems and difficulties that cannot be overcome, they will be hit, or even completely reversed, to the contrary, resulting in inferiority complex.

Therefore, college students should have a comprehensive and in-depth understanding of themselves and make an objective and correct evaluation of themselves. Understand what your strengths and weaknesses are compared with others; know what you can do and what you can't do; believe in yourself, accept yourself, strive for yourself, and not be frustrated by your weaknesses and shortcomings. We should not compare ourselves with others or ourselves with others; then we should give our life a correct orientation and establish a goal that is as close as possible to our own objective situation. Goals can neither be too high nor too low. If they are set too high, they will feel pressure, difficult to achieve, and easy to hurt self-confidence. If they are too low, they will easily be achieved and self-confidence will grow. Therefore, the objective self-evaluation of college students and the establishment of correct life goals are of vital importance to the promotion of mental health.

2) Establish correct values and look optimistically at the things around you

The reason why people can be called "the spirit of all things" is that people have a very complex and rich inner world, and values are its core. If we have the right values, we can have a correct understanding of our own life, the whole society and all kinds of things in the world, and we will treat them with appropriate attitude and behavior. We can stand taller and see farther than others, observe things scientifically, analyze things deeply, and handle things safely and correctly. We can keep an open-minded and indifferent attitude without rejoicing in things or grieving in ourselves.

3) Learn to self-regulate and improve the ability of psychological regulation

College students should strive to learn mental health knowledge and master effective methods of self-psychological adjustment. First of all, we should start from the cognitive point of view. We should clearly recognize our psychological state and personality characteristics, and set a practical goal for our study and life in school. Secondly, we should cultivate a healthy lifestyle, which is not a healthy lifestyle. We should develop good living habits, combine work with rest, use our brains scientifically, drink less, do not smoke, and persist in physical exercise.

Make the body and mind often in a state of pleasure. Once again, we should learn to self-adjust negative emotions and be the master of our own emotions.

College students will inevitably encounter various troubles and distresses in the process of life and learning, and will inevitably cause emotional fluctuations. We should learn to adjust according to different emotions and adopt different methods. The general adjustment methods are listening to music, chatting, writing diaries, walking, shopping and participating in various collective activities, so as to release their negative emotions in time. In addition, humor is also an effective way to relieve stress. Those students who are humorous are seldom depressed and anxious, and have a high sense of self-efficacy. Therefore, college students should strive to master all kinds of psychological adjustment methods, improve their ability of psychological regulation, ease the pressure of study and life, and improve the level of mental health. 


\section{B. Focus on College Physical Education Course Learning}

Physical exercise is not only physical activity, but also psychological and social activities. Physical exercise can regulate tension, improve mental state, improve physical health and relax fatigued body. In College Physical Education teaching, students should be allowed to understand the standard of mental health, so that students have a certain correct understanding of their own physical and psychological conditions. Participation in sports helps to enhance selfconfidence and overcome inferiority complex(2). For example, when trying to overcome difficulties to complete a sport, there will be a sense of success, self-confidence will also be enhanced. There are also such things as long-distance running, leaping and overcoming fatigue in sports, which can stimulate fighting spirit, cultivate willpower and enhance psychological endurance. By participating in collective sports, we can enhance the sense of cooperation, enhance the ability of social interaction, and promote harmonious interpersonal relations. At the same time, participating in sports can cultivate an open mind and the ability to deal with problems, which is conducive to the social environment. Adaptation to circumstances. Obviously, physical exercise helps college students' physical and mental health, so in the colleges and universities should pay attention to the teaching activities of physical education. In physical education classes, the interaction between teachers and students, students and students is extremely important. Harmonious classroom atmosphere is conducive to improving students 'interest and enthusiasm in physical education.

\section{Implementing Quality Education Policy and Strengthening Psychological Health Education in Primary and Secondary Schools}

At present, some of the psychological problems of college students are caused by the lack of mental health education in primary and secondary schools(3). And the lack of mental health education in primary and secondary schools is related to the excessive attention paid to academic performance and entrance rate in primary and secondary schools in China, and to the examination-oriented education system. In fact, as early as a decade ago, the Central Committee of the Communist Party of China and the State Council put forward that in the process of promoting quality education in schools, we must strengthen moral education and mental health education for students. However, the relevant supporting measures of the education sector are not effective, so that this policy can not be effectively implemented. Therefore, education Departments should take effective measures to implement quality education policies as soon as possible, guide primary and secondary school education objectives to students' physical, mental and intellectual development, and strengthen mental health education in primary and secondary schools. We can learn from the successful experience of the United States and offer psychological counseling courses in middle schools. Professional teachers systematically teach psychological health knowledge and coping strategies and methods of common psychological problems. We can also set up professional psychological counseling service departments to arrange psychological professional staff to prevent and treat students 'psychological problems. Offer help. In the primary school stage, the key is to give more attention and love to children by offering simple mental health courses and introducing simple mental health knowledge to students.

\section{Psychological Health Education Course Should Pay Attention to Practice}

Mental health education course is a public basic course, which is offered in every university. It is a comprehensive subject, including general psychology, teaching psychology, positive psychology, counseling psychology, clinical psychology and other disciplines. How to make this course scientific, practical and operable in the teaching process, help students to build up mental health awareness, prevent and alleviate psychological problems, enhance psychological adjustment ability and social adaptation ability, is our common concern.

Psychological health education curriculum should change the traditional teacher-centered teaching method and pay attention to the interaction between teachers and students. In order to make the teaching content close to students'real life, we try to enumerate some examples related to students' life in class. For the learning of teaching content, students can be divided into groups and discussed. Each group will send a representative to make a speech. Other students will supplement and express their views on this issue. Finally, the teacher will make a summary.

\section{E. Perfecting the Mental Health Education System in Colleges and Universities}

Liang Qichao, an outstanding enlightenment thinker and educator in modern China, once pointed out, "What is education?" Education is to teach people to learn how to behave - to learn to be a'modern'person. Therefore, the core of education is to teach people to behave themselves, and the process of education is the process of perfecting personality.

\section{1) Innovating the idea of higher education}

"Talents should not only master scientific knowledge, but also have perfect personality." (4)This is the consensus of the international community. Therefore, as colleges and Universities Undertaking the task of personnel training, we should clearly understand the importance of perfect personality for college students. We should innovate the concept of education, recognize that students are relatively independent individuals, they have their own nature and the right to choose their own way of life and learning; and put personality training in the first place. In school education, knowledge imparting is the first and knowledge imparting is the second, so as to establish a scientific and reasonable teaching system, adopt suitable education methods for post90 s College students, and create a perfect teaching environment for college students to become useful talents in the country.

\section{2) Opening compulsory courses of mental health education}

At present, our universities have basically set up optional courses in mental health education, including college students'psychological education, college students' interpersonal psychology(5), college students' psychological stress relief methods and other courses. Students can choose 
courses according to their interests and hobbies, but because it is an optional course, there are not many students who take part in the study. Moreover, due to the uneven professional level of teachers, different textbooks and outdated teaching methods, etc.

The teaching effect is satisfactory. Therefore, it is necessary to set up compulsory courses of mental health education in Colleges and universities. Through the opening of compulsory courses, all students can master mental health knowledge. The establishment of compulsory courses requires the use of professional, unified and specific teaching materials, standardization of teaching content, arrangement of full-time teachers, and guarantee the high quality of teachers. In addition, mental health education should run through the whole school education system. Teachers and counselors have the responsibility of mental health education for students. Only in this way can we provide a good campus environment for college students'mental health and ensure their mental health.

\section{3) Establishing a perfect psychological consultation institution}

At present, psychological counseling institutions are basically set up in Colleges and universities in China. However, due to insufficient personnel and other related supporting resources, there are still many problems in psychological counseling institutions in many schools, which can not run well. They often only solve some of the problems of some students, but also can not play a normal role in preventing and treating students'psychological problems. The role of improving students'mental health level. Therefore, colleges and universities should increase investment, improve the working conditions of psychological counseling institutions, equip professionals with rich experience in psychological counseling, establish relevant students'mental health files, and conduct systematic analysis and research.

To investigate the psychological problems of college students in different periods and under different environmental conditions(6), explore the regularity of students'psychological problems, and lay a foundation for helping students to prevent and treat psychological problems better in the future and giving full play to the role of psychological counseling institutions.

The practice of the United States is worth learning from. American universities have set up special psychological counseling and treatment institutions for students. They serve all students. Their daily work is to provide counseling or treatment services for students with mental disorders. In addition, they arrange group therapy for students with high frequency of mental problems every semester. Most school counseling and treatment institutions have special webpages on their websites. Students can learn about counseling and treatment institutions through the network. Such as service content, service time, staff composition, contact mode, charging standards and general knowledge of mental health, etc.

\section{CONCLUSION}

Maintaining healthy psychology is not only related to the cultivation of College Students' good morality and the formation of perfect personality, but also to the overall improvement of talents' quality, the overall realization of higher education goals, and even the smooth progress of modernization. This is a problem that needs the common attention and research of colleges and universities.

\section{REFERENCES}

[1] Dong Hui, Ma li. Reform and Exploration of Mental Health Education for College Students [J]. Journal of Liaoning Teachers College, 2012.

[2] Cui Bin. A Brief Analysis of College Students' Mental Health Consultation [J]. Journal of Fu yang Normal University, 2010.12.

[3] Zhang $\mathrm{Na}$, on the causes and Countermeasures of College Students 'psychological problems [N], Journal of Shanxi Radio and Television University,2014.

[4] Li Yu, Gao Yao hong, Xie Feng Juice, Problems and Countermeasures of College Students 'Mental Health Education [J], Contemporary Education Forum, 2014

[5] Liu Yidi, Mental Health Status of Poor Students in Colleges and Universities in China and Its Countermeasures [D], East China Normal University, 2015.

[6] Ren Xiujie, based on the cultivation of College Students' psychological quality $[\mathrm{J}]$, career space and time,2012. 